\title{
The Roles of Genetics in $A \beta$ related Alzheimer's Diseases
}

\author{
Yin Tian*, Zhongyan Wang, Zechao Ding, Huiling Zhang \\ Bio-information College, ChongQing University of Posts and Telecommunications, ChongQing 400065, China \\ *Corresponding Author: E-mail: tiany20032003@163.com; Tel.: +86-23-62460536; Fax: +86-23-62460536
}

Received: June 18, 2015; Revised: August 09, 2015; Published: September 05, 2014

\begin{abstract}
About 35 million people worldwide were suffered from Alzheimer's disease (AD) in 2014 and the number of patients was expected to increase by 4-fold in 2050. As a neurodegenerative disease impacting our society, the pathogenesis and prognosis of $A D$ have not yet fully understood. Senile plaque is generally regarded as one of the hallmarks of the disease, which may be due to the imbalance of AB peptides in the brain. Over the last decades, studies of early onset familial $A D$ have led us to a deeper understanding of the genetics and molecular biology of $A D$. There is increasing evidence to suggest that the pathogenesis of $A D$ is more likely to be caused by multiple genetic mutations. However, the precise genetic component leading to $A D$ pathogenesis remains unclear. In this review, we will briefly introduce the classification of $A D$ in the context of genetics. Then we will discuss the gene mutations in chromosome 21, 19 and presenilin as well as their links to AB peptides. Imaging data will be discussed alongside to complement the associated structural and physiological changes in the brain. It is our hope that future research in genetics will continue to enhance our understanding of the pathogenesis of $A D$ and the mechanisms leading to the formation of senile plaques.
\end{abstract}

\section{Keywords}

Neurobiological pathogenesis; senile plaque; $A \beta$ peptide; amyloid precursor protein; genetic mutation

\section{Introduction}

Alzheimer's disease (AD) is a neurodegenerative disease in which the cognitive decline of the patient progresses over time. It is one of the most common diseases of senile dementia symptoms, including waning memory, and cognitive dysfunctions, such as time, place, character, emotion, as well as personality changes. Severe AD patients could suffer from language obstacles leading to difficulties in daily communication. With the continuous improvement of living standard and life-span, the incidence rate of $A D$ is rising. As of 2014, the number of $A D$ patients has reached 35 million. In 2050, the number of $A D$ patients will exceed 100 million. Currently, the US has over 5 million AD patients, with an annual cost to the healthcare system over $\$ 200$ billion. From now to 2050, the cost of treatment for AD will reach $\$ 20$ trillion [1]. These represent a significant burden on the nation resource. Clearly, a good understand on the pathogenesis and prognosis of $A D$ is very important.

\section{Classification of Alzheimer's disease in the context of genetics}

$A D$ can be classified according to the age of the patient, namely age early and late AD. Early onset $A D$ 
(EOAD) occurs in patients younger than 65 years old, while for the late onset AD (LOAD) the patients are older than 65 years. One of the distinct pathological characteristics of $A D$ is the presence of amyloid- $\beta$ plaques in the brain [2]. Regardless of EOAD or LOAD, the pathogenesis is more or less associated with genetics. Gatz et al believe more than half ( $60 \%-80 \%)$ of the AD pathogenesis is influenced by genetics, which is referred to as the familial AD (FAD) [3]. Although the etiology and pathogenesis of AD is not completely understood, there are clear evidence suggest that gene mutations lead to extracellular deposition of amyloid- $\beta(A \beta)$ and subsequently the formation of senile plaque, which is one of one of the characteristic pathological changes in $A D[4,5]$. These $A D$ disease genes are family associated and mostly autosomal dominant, with the FAD gene located on chromosome 21, 19, 14 and 1 . On the 21, 14, and 1 chromosome, the mutations are linked to EOAD. On the 19 chromosome carrying Apolipoprotein E (ApoE), the mutations are linked to LOAD [2]. Most of the pathogenesis of AD is not solely determined by a single gene. Instead, it is more likely to be caused by multiple genes and environmental factors, together with genetic mutation $[6,7]$. However, the precise genetic component leading to $A D$ pathogenesis remains unclear.

\section{Mechanisms of $A D$ related to $A \beta$}

Based on the pathological mechanism of $A \beta$ in the formation of senile plaques, this review will explore the pathology evidence and functional evidence of $A D$ in the context of genetics. Literature evidence suggested that there exists dynamic equilibrium between brain extracellular $A \beta$ generation (production) and clearance (clearance). When the balance is upset, $A \beta$ accumulation (accumulation) and aggregation (aggregation) begin [8-10]. Neurotoxic $A \beta$ aggregation leads to the formation of plaques of amyloid- $\beta$, resulting in $A D$ patients with dementia and other cognitive disorders. In addition, we will discuss other genetic factors leading to AD pathogenesis and the prevention mechanisms (see Fig. 1).

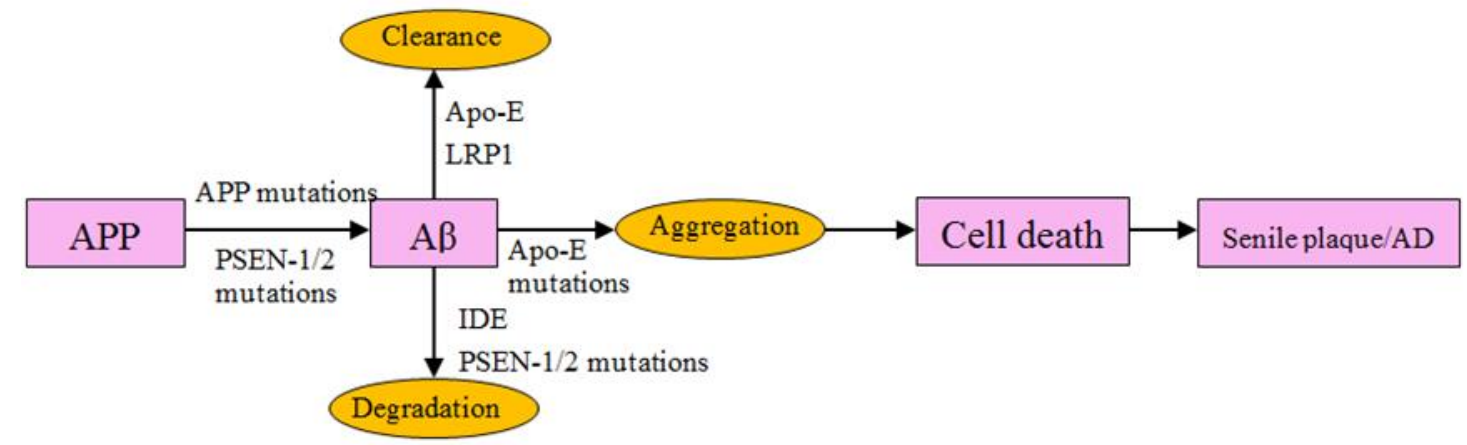

Figure 1. Hypothesis on $A D$ based on mutations associated with $A \beta$ peptides. The rationale behind this hypothesis is that genes and gene mutations affect the production, clearance, degradation and aggregation of $A \beta$. These metabolic processes, if not in balance, may lead to cell death, the formation of senile plaques and increased $A D$ risk.

\section{Chromosome 21:}

\section{Formation of $A B$}

Autosomal dominant inheritance $A D$ and/or family EOAD are closely related to the amyloid precursor protein (APP) on the chromosome 21. Specifically, the hydrolysis of APP by $\beta$-secretase and $\gamma$-secretase complex leads to the formation of hydrophobic amyloid- $\beta$ [11]. At the same time, hydrolysis lead to the formation of water soluble APP intracellular structure (AICD), which could result in apoptosis. In addition to 
the production of amyloid- $\beta$, APP can be hydrolyzed by the $\alpha$-secretase enzyme to form 3-kDa product (P3), AICD and soluble APP extracellular domain (SAPP $\alpha$ ), which has a neuroprotective effect $[12,13]$. Excessive sAPP $\alpha$ can also suppress the formation of toxic $A \beta$ [11]. As shown in Fig. 2, sAPP $\beta$, A $\beta$ and AICD are generated in the 671/672 locus of APP via the $\beta$-secretase enzyme hydrolysis, while SAPP $\alpha, P 3$ and AICD are produced in the $687 / 688$ locus of APP by $\alpha$-secretase. The formation of $A \beta_{40}\left(A \beta_{42}\right)$ is accomplished by hydrolysis of APP with $\beta$-secretase through $\gamma_{40}\left(\gamma_{42}\right)$ in which $\gamma_{40}$ and $\gamma_{42}$ are kinds of $\gamma$ secretase (see Fig. 2). Choy $R$ et al reported that $A \beta_{40}$ is mainly produced in trans-Golgi network (TNG). After the detachment of TNG from the nucleus, the APP aggregation in endosomes reduced, so as the accumulation of $A \beta$ [13]. In APP transgenic mice, it has been found that the loss of neuronal cysteine protease cathepsin $B$ (CatB) led to in increased amyloid plaque load and increased $A \beta_{1-42}$ to $A \beta_{1-40}$ ratios. In early APP transgenic mice, the expression level of CatB elevated. This leads to the denaturation of $A \beta$, resulting in the inactivation of $A \beta$ oligomers and reduction of $A \beta$ fibers [14].

\section{APP gene mutations: which one affecting $A B$ ?}

As shown in Fig. 2, APP is modified by mutation to form toxic A $\beta$. Accumulation of these toxic peptides increases the risk of getting $A D$. Usually, the mutation occurred at the cleavage site $\beta$-secretase enzyme $(A \beta)$ near the Swedish KM670 / 671NL. With this mutation, the intracellular A $\beta$ formation is about 6 to 8fold more likely than wild type [15]. However, whole-genome sequencing revealed that A673T mutation in APP was indeed due to the $\beta$ site being replaced, which led to the decrease in extracellular $A \beta$ peptides. For the elderly people that do not suffer from AD, the knowledge on A673T mutation may offer predictive and/or preventive measures for cognitive decline [16].

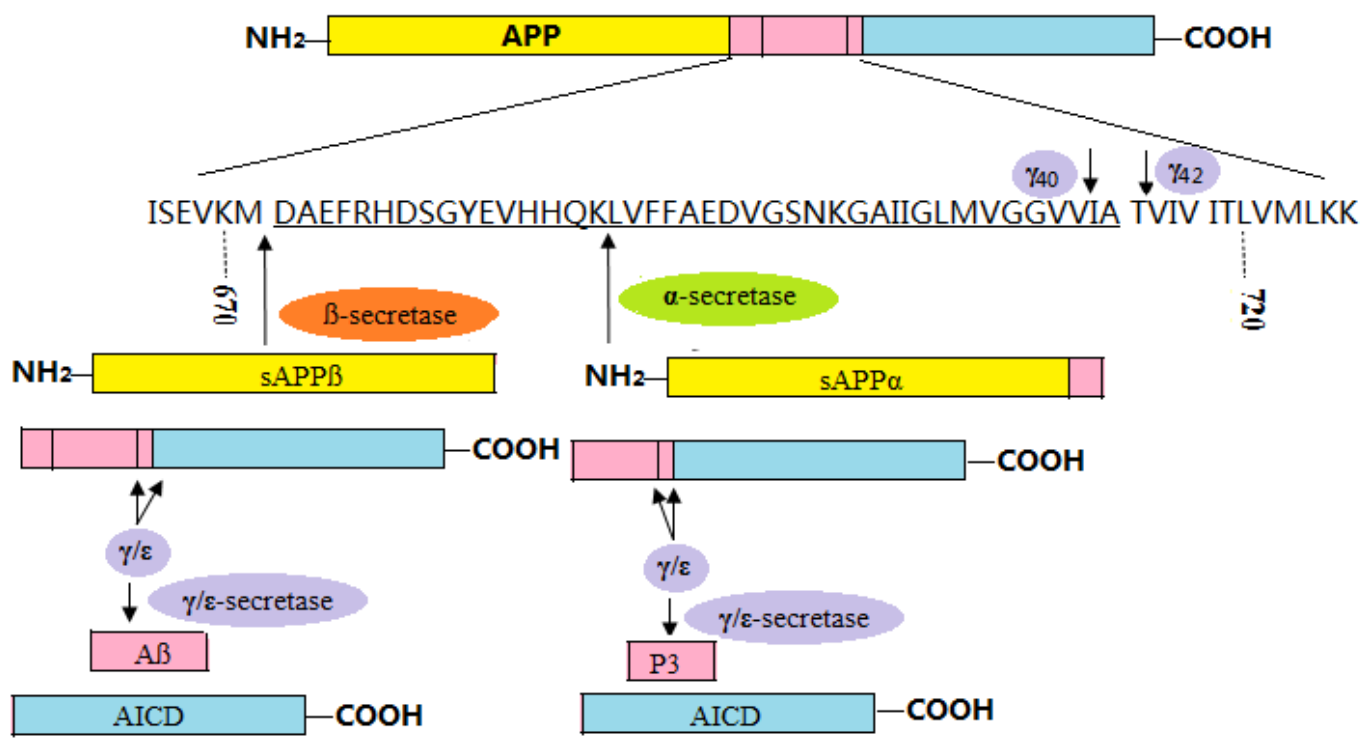

Figure 2. Schematic to show the hydrolysis of APP and the formation of A (APP gene on chromosome 21 mutation, abnormal hydrolysis to produce toxic $A \beta$ ). APP is hydrolyzed into peptide fragments (with $A \beta$ marked pink), including soluble SAPP $\beta, A \beta, A I C D$ or SAPP $\alpha, P 3$ and AICD. The formation of $A \beta_{40}\left(A \beta_{42}\right)$ is accomplished by hydrolysis of APP with $\beta$-secretase through $\gamma_{40}\left(\gamma_{42}\right)$.

In case of homozygotes, $A 673 \mathrm{~V}$ (valine-673) gene mutation increases the generation of $A \beta_{42}$ and $A \beta_{40}$ simultaneously, thereby increasing the accumulation of amyloid fibrils in vitro. However, the same mutation shows the opposite effects on $A \beta_{42}$ and $A \beta_{40}$ in the heterozygotes [17]. More SAPP $\alpha$ is generated via the hydrolysis of APP at allele 690 and 692 by the substitution of alanine and phenylalanine, respectively. At the same time, the generation of $\mathrm{P} 3$ peptide is reduced, which facilitates the increase of 
$A \beta_{40}$ and $A \beta_{42}$ [18]. For Arctic E693 mutation carriers, the levels of $A \beta_{42}$ and $A \beta_{40}$ in plasma are lower than that of wild type. Yet, the rate of $A \beta$ generation in the mutants is faster, which may reflect another possible disease mechanism associated with $A D$ [19]. At the $\gamma$ cleavage sites, the A713T mutation can lead to cerebral amyloid angiopathy symptoms, which is also associated with AD [20].

In Iranian FAD, allele Thr714Ala may induce a remarkable increase in the $A \beta_{1-42} / A \beta_{1-40}$ ratio (up to 11 times) [21]. Recently, Sieczkowski $E$ found that I716F $\beta A P P$ is a mutation associated with glutamate-A $\beta$, which increases the generation of senile plaques and nerve tangles [22]. The APP 717 mutation increases the production of the soluble $\beta A P P, A \beta 42$ and $A \beta 38$, which are associated with dementia [23-25]. The newly discovered K724 mutation in China (40-58 years old) has been shown to enhance the $A \beta_{1-42} / A \beta_{1-40}$ ratio (over 2-fold). Monitoring this mutation may provide preventive measures for early-onset FAD in China [26]. Another mutation K16N, which is situated at the $\alpha$ hydrolysis sites, may provide information on earlyonset $A D$ risk. $K 16 \mathrm{~N}$ affects the $A P P$ alleles and the formation of longer $A \beta$ peptides (e.g. from $A \beta_{40}$ to $A \beta_{42}$ ). Although the $A \beta$ peptide itself does not show cytotoxic effects, equimolecular mixture of both wild type $A \beta$ and mutant type $A \beta$ is far more toxic. In addition, $K 16 \mathrm{~N}$ inactivates the $A \beta$-degrading enzyme, neprilysin, affecting the elimination of $A \beta_{42}$ peptide [27]. The $D 7 H$ mutation could increase the $A \beta_{1-42}$ production and the $A \beta_{1-42} / A \beta_{1-40}$ ratio (approximately 2-fold), and the resulting $A \beta_{1-42}$ peptide becomes more toxic. In the presence of $\mathrm{Zn}^{2+}$ or $\mathrm{Cu}^{2+}, \mathrm{D} 7 \mathrm{H}-\mathrm{A} \beta$ aggregates to form oligomers. Hence, D7H allele can be used to increase D7H-A $\beta$ the production and aggregation $[28,29]$. H6R mutations increase the toxicity of all subtypes (isoform) and their rate of fiber formation. Due to the increase in $A \beta$ dimers and $C$-terminal monomers, $A \beta_{42}$ fiber forming time is shortened [30]. APP mutations not only can direct the $A \beta$ generation (production), clearance (clearance), accumulation (accumulation), aggregation (aggregation) to influence the potential risk of $A D$, but also can increase the fat content of the body, indirectly enhancing the risk of $A D[31]$.

\section{APP imaging modalities: changes of $A B$ in brain atrophy}

A wide range of imaging modalities, such as MRI (Magnetic Resonance Imaging), functional MRI, 11CPiB (carbon 11-labeled Pittsburgh Compound B) PET (positron emission tomography) imaging have been utilized in supporting $A D$ research [32,33]. In particular, some of these techniques enable the in situ detection and monitoring of senile plagues in AD patients [34]. These may provide evidence on the research of APP mutation and pathology evidence to enable the identification of the early signs of AD.

Mutation of APP-E693 $\triangle$ was found in cases of early FAD. The AD patients with the AD E693 $\triangle$ mutation exhibit a memory dysfunction and partial brain atrophy. However, senile plaques are rarely seen, which may be due to low level of accumulation of $A \beta$ in vivo [32]. According to 11C-labeled PiB-PET and 18F-FDGPET imaging, a significant difference between the Arctic APP (APParc) and Sweden (APPswe) mutations on APP has been observed [33]. APParc mutation carriers show low level of absorption of PiB in cortex, while the rate of glucose metabolism in the brain and the $A \beta_{42}$ levels in cerebral spinal fluid (CSF) are low. APPswe mutation carriers absorbed more PiB in cortex, with the cerebral glucose metabolic rate reduced, which was especially obvious in the striatum. The $A \beta_{42}$ level in CSF was increased significantly [33]. In contrast with the cerebro-absorption of $11 \mathrm{C}-\mathrm{PiB}$ in sporadic AD patients, FAD with APP mutation carriers show large increases in absorption in striatum, posterior cingulate (caudate nucleus, putamen), while absorption in other cortical areas also show small increases [34]. In addition to the frontal lobe, the temporal lobe, occipital lobe and posterior cingulate cortex and other brain areas show increased absorption of $11 \mathrm{C}-\mathrm{PiB}[35,36]$. According to $\mathrm{fMRI}$ data, APP allelic variations can lead to increased activity in brain middle temporal gyri (MTG) and left fusiform gyri regions [37]. In summary, APP mutations may 
affect the accumulation and deposition of $A \beta$ and other cortical regions (see Fig. 3). This may also change the rate of glucose metabolism in the cerebral cortex and other regions of the striatum, resulting in an increased risk of synaptic dysfunction in $A D$ patients. Further investigation will be required to understand the APP mutations and the exact mechanisms in regulating $A \beta$.

\section{Chromosome 19: (APOE)}

The effects of $A P O E$ on the clearance of $A B$ : impacts of $\varepsilon 2, \varepsilon 3, \varepsilon 4$ on $A B$

The APP mutation mostly alters the generation of amyloid- $\beta$, which affects the AD pathogenesis. In marked contrast, the apolipoprotein $E$ (Apo-E) in chromosome 19 works by clearing the amyloid- $\beta$ to reduce the risk of $A D$. If there is no mutation, Apo-E plays the role of clearing the soluble amyloid- $\beta$. With the aid of Apo-E, the activity of neprilysin is enhanced for the elimination of intracellular $A \beta$. In extracellular environment, the elimination of toxic $A \beta$ is accomplished by Apo-E related insulin degrading enzymes. Thus, Apo-E isoforms can enhance the degradation of $A \beta$, while lipidated Apo-E can also be useful to accelerate the $A \beta$ clearance [38].

Unlike Apo-E gene, Apo-E has three alleles $\varepsilon 2, \varepsilon 3, \varepsilon 4$, which can promote the formation of hydrophobic $A \beta$ and reduce the clearance of toxic $A \beta$, which increases the potential risk of AD [39]. APOE may be combined with hydrophobic $B-A P$, which induces the formation of $B-A P$ monofilament and precipitation. Comparing with the allele $\varepsilon 3, \varepsilon 4$ forms a stronger bonding between the carrier protein Apo-E4 and B-AP. In cases of the Apo-E $\varepsilon 4$ homozygous individuals, the amount of B-AP precipitation in brain is far more than that of the Apo-E $\varepsilon 3$ gene homozygous individuals. In the B-AP fibrous structure formation, Apo-E played an important role in the formation of senile plaques.

For $A D$ patients containing $\varepsilon 2, \varepsilon 3, \varepsilon 4$ mixing genes in the brain, individuals with $\varepsilon 4$ allele show higher incidence rate, while individuals with of $\varepsilon 2$ allele show lower incidence rate [39-42]. For very elderly patients (90 years or more), Apo-E $\varepsilon 2$ associated with intact cognition (dementia associated risk reduced). However, the increase in Apo-E $\varepsilon 2$ associated with $A D$ related neuropathology [40]. Autopsy on $A D$ patients revealed that most of the $A \beta$ peptide accumulation and precipitation genotypes are: Apo-E $\varepsilon 3 / \varepsilon 4$ $(\varepsilon 3 / \varepsilon 4>\varepsilon 3 / \varepsilon 3>\varepsilon 2 / \varepsilon 3)$. The Apo-E $\varepsilon 4$ homozygotes carriers are generally dementia [41]. However, the age of $A D$ diagnosed is negatively correlated with the risk of incidence. Apo-E $\varepsilon 4$ gene is related to the lowest age of $A D$ diagnosed, while Apo-E $\varepsilon 2$ gene is related to the highest age of $A D$ diagnosed. For Apo-E $\varepsilon 3$ gene, the age of $A D$ diagnosed and the risk of incidence are between that of $\varepsilon 4$ and $\varepsilon 2$ [42].

\section{Apo- $E \& 4$ and other factors that affect $A D$}

It has been reported that the vast majority of $A D$ patients (approximately $65 \%-75 \%$ ) carry Apo-E $\varepsilon 4$ allele. The distribution of Apo-E allele varies among different races and geographical locations. Usually near the equator and in the Arctic region, populations carry higher frequency of Apo-E $\varepsilon 4$ allele [43]. For the Chinese people, the risk of AD incidence with Apo-E $\varepsilon 4$ allele was 3.93 times above average. In particular, $\varepsilon 4$ homozygous genotype is a risk factor for $A D$; while Apo-E $\varepsilon 3$ carriers show the risk of $A D$ incidence lower than average [44]. Apo-E $\varepsilon 4$ allele may also affect patient LOAD by reducing (approximately halved) the insulin-degrading enzyme (IDE) in the hippocampus. The main function of IDE is the degradation and removal of amyloid- $\beta$ in the brain. The involvement of Apo-E $\varepsilon 4$ and IDE in amyloid- $\beta$ metabolism increases the risk of $A D[45]$. 
Before the onset AD (about 70 years), Apo-E allele and brain-derived neurotrophic factor (BDNF) lead to the brain's cognitive decline. In 4.5-year time, comparing to $A \beta$ and $\varepsilon 4$ noncarriers, $A \beta / \varepsilon 4$ carriers showed significant cognitive decline, while individuals carrying $A \beta$ without carrying $\varepsilon 4$ show only vocabulary cognitive decline. In $A \beta$ carriers (4.5-year later), comparing with the $\varepsilon 4$ noncarriers, and $\varepsilon 4$ / BDNFMet carriers (brain derived neurotrophic factor Met), the vocabulary and visual episodic memory decreased significantly faster.Regardless of the status of BDNF and Apo-E (4.5-year later), only little cognitive decline was observed in non-ع4 carriers [46].

In the mice blood-brain barrier (BBB) model, it has been shown that Apo-E allele undermines the clearance of neurotoxic $A \beta$ peptides (destructive effects: Apo-E4 is greater than that of the Apo-E3 and Apo-E2) [47]. In this context, $A \beta$ peptides bind to $A p o-E 4$, resulting in a rapid removal of free $A \beta_{1-40} / A \beta_{1-42}$. The Apo-E4 inside the BBB can form complex with $A \beta$, which is significantly slower than that with LRP1 (LDL (low density lipoprotein) receptor-related protein 1). In contrast, the Apo-E2 and Apo-E3 on the BBB can form complex with $A \beta$ in VLVLR (VLDL (very low density lipoprotein) receptor) and LRP1, where the clearance rate is faster than that of the A $\beta$-Apo-E4 complex [8]. The brain Apo-E allele offers different models of clearance for $A \beta$, which may help to understand the disease progression of $A D$ in animal/human models.

\section{$P E T, M R I, D T I$ and fMRI imaging for Apo-E $\varepsilon 4$ and their influences on brain networks}

As shown in Fig. 3, using the florbetapir (18F-FDG) positron emission tomography (PET) imaging technique, it has been shown that the APOE alleles in chromosome 19 and butyrylcholinesterase (BCHE) can be regarded as $A \beta$ peptide deposition regulator [47]. In cognitively normal $A D$ patients, the cortex glucose metabolism rate $(\mathrm{CMRg})$ is significantly reduced for Apo-E $\varepsilon 4$ carrier $[\varepsilon 4+]$, especially in the front frontal lobe, parietal lobe, temporal lobe and posterior cingulate regions [48-52].
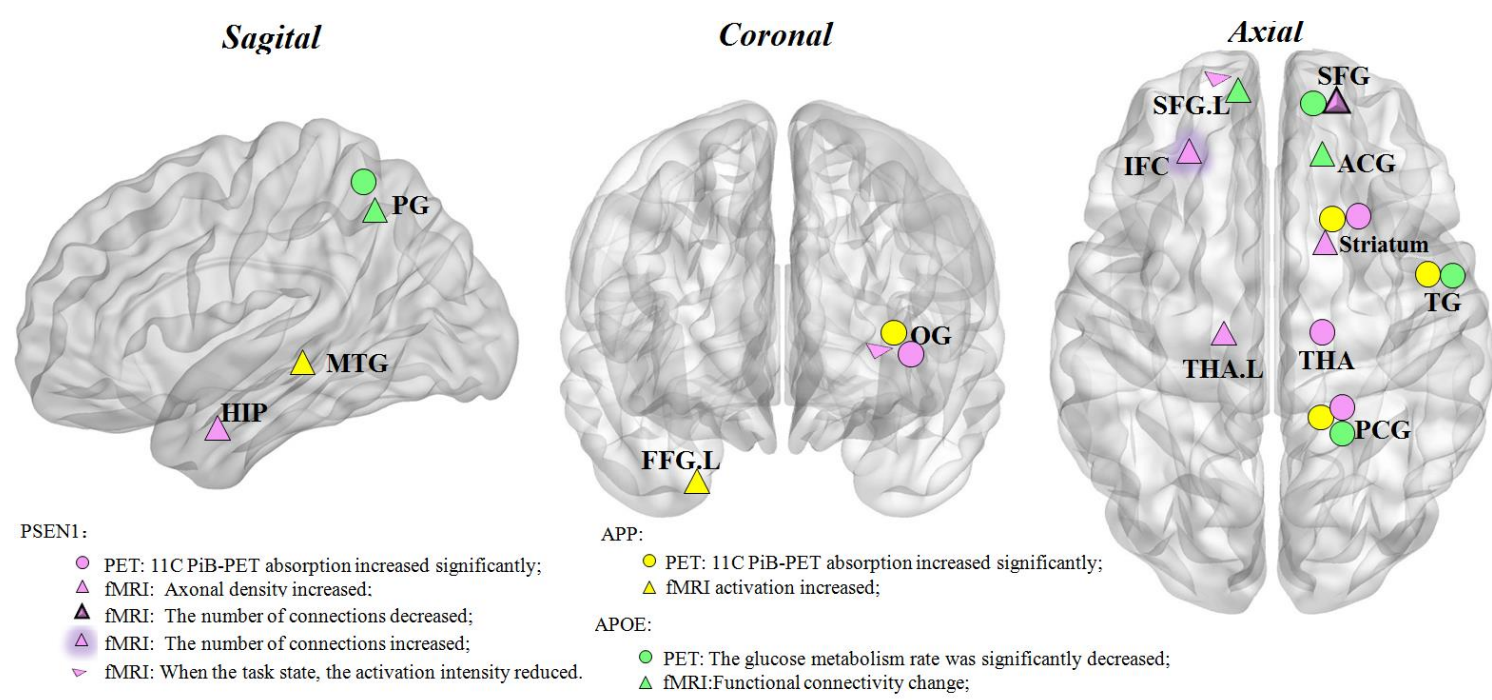

Figure 3. Schematic to shows the APP, APOE, PSEN mutations causing changes in the brain function. APP gene mutations resulted in the increase in the absorption of $11 \mathrm{C}-\mathrm{PiB}$ in striatum, posterior cingulate gyrus (PCG), temporal gyrus (TG), occipital gyrus (OG), with the middle temporal gyri (MTG) and left fusiform gyri (FFG.L) activation increased. Apo-E $\varepsilon 4$ allele mutations significantly reduced the superior frontal gyrus (SFG), parietal gyrus (PG), TG, PCG cortex glucose metabolism rate (CMRgI) and altered functional connectivity in brain regions including: PG, left SFG (SFG.L) and anterior cingulate gyri (ACG). PSEN1 gene mutation carriers showed significant increase in the absorption of PiB in striatum, ACG, PCG, thalamus and OG cortex. The axonal density increased in left thalamus (THA.L), striatum, hippocampus (HIP). Network characteristics changed including the default network connection, reduction of the SFG connections and increase in the inferior frontal gyrus (IFG) connections. The task state and the activation strength of LSFG and OG were reduced. 
Apo-E $\varepsilon 4$ dose is related with higher and earlier risk of dementia [50]. The hippocampal volume, the hippocampal glucose metabolism and posterior cingulate glucose metabolism are closely related to Apo-E $[\varepsilon 4+]$ gene. Among these, the correlation of posterior cingulate glucose metabolism and Apo-E $[\varepsilon 4+]$ allele is significantly greater than the correlation of hippocampal volume, glucose metabolism and Apo-E $[\varepsilon 4+]$ allele [50].

MRI imaging has been used to study the cortical thickness in Vietnamese men. It has been shown that in the Apo-E homozygote-carriers $[\varepsilon 3+]$ and the brain regions of Apo-E $\varepsilon 3 / 4$ carriers, the frontal lobe, the left front and right rear volume central region are significantly thinner ; for Apo-E $\varepsilon 2 / 3$ carriers, the right parahippocampal cortex region is relatively thick, which may be due to natural aging [53]. Diffusion tensor imaging (DTI) of T1 structure imaging revealed that Apo-E carrier $[\varepsilon 4+]$ loss the interconnection faster than that due to aging, especially in the medial prefrontal orbital frontal cortex, precuneus and outer local parietal cortex region where the connectivity is reduced [54].

In a picture learning experiment using fMRI monitoring, Apo-E carriers $[\varepsilon 4+]$ show enhanced BOLD signal during learning. This suggests that Apo-E4 allele in older adults with $A D$ exhibit greater genetic risk with cognitive-related episodic memory [55]. There are significant functional connectivity changes in parietal lobe, left frontal regions and anterior cingulate [56, 57]. For Apo-E carriers $[\varepsilon 4+]$, network connections were reduced in the left middle temporal gyrus, left parietal lobe, regional connectivity bilateral anterior temporal lobe, but were enhanced in bilateral insular cortex, cingulate, connectivity striatum and thalamus medial prefrontal cortex [56].

During memory activation task, Apo-E carriers $[\varepsilon 4+]$ show increased brain activation in the parietal lobe, left hippocampus and the prefrontal region. During the recall memory task, the signal density increases particularly in the hippocampus region with Apo-E carrier $[\varepsilon 4+]$ greater than $[\varepsilon 3+]$. The average number of whole-brain activation area also increases [57]. Apo-E carrier [ $\varepsilon 4+]$ topology of the whole brain significantly impaired and the amount of parallel transmission of information reduced. Moreover the connections between the rear default mode network ( $p-D M N)$ and other brain functions were decreased. ECN, p-DMN and sensory-motor system also showed abnormalities and global topology damaged [58].

Thus, Apo-E plays a role in the elimination of $A \beta$. With Apo-E genetic mutations, amyloid- $\beta$ clearance is compromised, leading to $A \beta$ accumulation. Regional, environmental, age and other factors could affect the Apo-E genetic mutations. Comparing with the Apo-E carrier $[\varepsilon 3+]$, Apo-E carrier $[\varepsilon 4+]$ is more likely to be an AD patient.

\section{Presenilin (PSEN)}

\section{Mutations in PSEN, PSEN-1 and PSEN-2}

Presenilin (PSEN) is a transmembrane protein that functions as a part of the $\gamma$-secretase intramembrane protease complex. PSEN regulates protein transport and aberrant protein synthesis. Clearly, protein dysfunctions can affect $\beta A P P$, which could accelerate the development of $A D[59,60]$. In Presenilin-1 (PSEN-1) gene and its homologous genes Presenilin-2(PSEN-2), the most common mutations occur in chromosome 14 and chromosome 1, which could lead to EOAD. However, the N141l mutation in the 342/343 position of PSEN-2 is linked to EOAD and LOAD [61]. In transgenic mice model, it has been shown that PSEN-2/N141I mutation can reduce the $A \beta 40$ level, but produce more neurotoxic $A \beta 42$ leading to the $A \beta_{1-42} / A \beta_{1-40}$ ratio increases, and undermining the $A \beta$ clearance [62].

The mutations in PSEN-2 mainly include: A85V, T122P, T122R, E126K, V148I, M174V, S175C, Q228L, 
Y231C, M239I, M239V, T430M and D439A. These mutations could lead to EOAD [63-66]. Among these, T122R mutation modifies nerve fibers and M239 increases the production A 342 peptide, which are all dementia-related. Overexpression of PSEN-2 may promote $A \beta 42$ fragments induced apoptosis $[64,65]$. For PSEN-1, mutation mainly changes the activity of $\gamma$-secretase thus enhancing the generation of $A \beta$ peptides. The M146L, L166P and N141I mutations in PSEN-1 could lead to a functional impairment of $\gamma$-secretase, and inhibition of endogenous generation of $A \beta 1-40$, leading to an increase of $A \beta_{1-42}$ and the $A \beta_{1-42} / A \beta_{1-40}$ ratio [67-69].

The PSEN-1/G384A mutation is due to the accumulation of intracellular $A \beta$ hydrolyzate ( $>A \beta_{1-42}$ ), which slows down the rate of degradation of $A \beta$ in the cell membranes. After a long period of time, the $A \beta$ hydrolyzate eventually degrades. Although this had no effect on the generation of $A \beta_{1-42}$, the $A \beta_{1-40}$ level was reduced [70]. In transgenic mice, heterozygous carriers with PSEN-1/R278I mutation express higher level of neurotoxic $A \beta_{1-43}$ peptide, thus inhibiting the expression level of normal $A \beta_{1-40}$ peptide. Embrynoic lethality was observed in homozygous carriers, indicating that the PSEN-1/R278I mutation could lead to physiological defects [71].

PSEN-1/I213T and PSEN1/C410Y mutations reduce the generation of $A \beta_{1-40}$ and $A \beta_{1-42}$ peptides $[72,73]$, which is mainly due to the PSEN-1/I213T mutation destroys the APP C-terminal fragment of the cleavage $\gamma$ sites. Thus, the total reaction rate $\gamma$-secretase is reduced, resulting in an increase of $A \beta_{1-43}, A \beta_{1-45}$ exceeding the $A \beta_{1-46}$ production [72]. In PSEN-1 mutations, regardless of increase or decrease in the $A \beta_{1-40}$ and $A \beta_{1-42}$ levels, the $A \beta_{1-42} / A \beta_{1-40}$ ratio always increases, resulting in neurotoxicity and increased risk of EOAD.

\subsection{PSEN-1 mutations affect the degradation of $A \beta$}

$\gamma$-secretase complex is one of key components for the hydrolysis of APP into A $\beta$ peptides. In case of AD, PSEN-1 mutations significantly affect the activity of $\gamma$-secretase complex and alter AICD thereby increasing the $A \beta_{1-42} / A \beta_{1-40}$ ratio [74]. Through the use of $\gamma$-secretase, PSEN-1 FAD-linked mutations can degrade $A \beta$ peptides, with the degradation pathways as follows:

$$
A \beta_{49} \rightarrow A \beta_{46} \rightarrow A \beta_{43} \rightarrow A \beta_{40}
$$

and

$$
A \beta_{48} \rightarrow A \beta_{45} \rightarrow A \beta_{42} \rightarrow A \beta_{38}
$$

This increases the neurotoxicity by increasing the $A \beta_{1-42} / A \beta_{1-40}$ residue [75]. Moreover, in vitro and cell internal PSEN / $\gamma$-secretase offer additional degradation pathway: $A \beta_{43} \rightarrow A \beta_{38}$.In contrast, the PSEN mutant acts on $\gamma$-secretase by inhibiting the degradation of longer A $\beta$. PSEN / $\gamma$-secretase can minimize the functional loss of $A \beta 42$ and $A \beta 43$, which could in turn help to prevent $A D[76]$.

Of course, the lower the toxicity of $A \beta 42$ peptide and increase $y$-secretase modulators (GSMS) can be fed back to the TMD-1 (transmembrane domain) of PSEN-1 to change its structure. In TMD-1 abnormal secretions include $A \beta_{45}$ and longer $A \beta$ peptides. TMD-1 helical surface comprises the binding function of $A \beta_{45}$ and $A \beta_{48}$. This combination changes the encoding mutations of the GSMS and TMD-1. At the same time, such a combination facilitates the formation of the hydrophobic $A \beta_{42}$ [77].

\section{PSEN-1 imaging study and regional shrinking effects}

With the aid of cerebrospinal fluid, plasma markers, structural MRI and fMRI studies, it is possible to assess the risk factors of EOAD in PSEN-1 autosomal mutations. In PSEN-1/E280A mutation carriers, it has been observed that the average age showing $A \beta$ toxicity was 28 , while the average age showing cognitive 
impairment was 44 [78]. Klunk WE, et al. reported that in the PSEN-1/C410Y FAD-linked mutation carriers, striatal significant $A \beta$ deposition has been observed in striatum, which led to cortical lesion. However, the lesion area is significantly smaller than that of sporadic AD patients [79].

The use of 11C-PiB PET measurements further confirmed that the PSEN-1 striatal lesions were indeed caused by mutations. Compared with AD patients without PSEN-1, the striatum of the mutation carriers exhibited a considerably higher uptake of PiB. Beside, anterior cingulate, posterior cingulate, thalamus and occipital cortex cortical areas have also shown significant enhanced uptake of PiB [80]. In presymptomatic FAD, it has been shown that in PSEN-1 mutation carriers, the left thalamus and caudate nucleus shrank significantly. The density of axons, right hippocampus and right cingulate axon density were also reduced. In cases of FAD, axon density in hippocampus and caudate nucleus increase. This may be due to the intensive axonal lesion area further extending to the entire brain networks [81].

For PSEN-1 mutation carriers, a decrease in the glucose metabolic rate has been observed in PCC, bilaterally inferior parietal lobule, superior temporal gyrus, hippocampus and left entorhinal cortex regions [82]. When PSEN-1 mutation carriers undergo a visual coding task, resting-state fMRI shows the default network changes, which include a reduction in the number of connections in the frontal lobe, an increase in the number of connections at frontal rear increases. At the task state, the activation strength at the left prefrontal cortex and occipital are reduced, while posterior cingulate and precuneus activation are enhanced (see Fig. 3) [83].

\section{Conclusion}

Overall, the gene mutations in chromosome $21,19,14$ and 1 in the context of $A D$ are less than $30 \%$. More genetic risk factors leading to $A D$ have yet to be discovered [5]. Currently, chromosome 12, 10 and 9 are found to be genetically related to $A D$. Chromosome 10 mutations increased intracellular $A \beta_{1-42}$ peptides and plasma $A \beta$. Chromosome 10 and 12 mutations also increased the risk of FAD-linked LOAD [84-85]. Finally, research in $A D$ pathology and function in the context of genetics will continue to enhance our understanding of the pathogenesis of $A D$ and the formation of senile plaques. Through the regulations of $\alpha$-, $\beta$ - and $\psi$-secretases, it may be possible to help restoring the homeostasis of $A \beta$, which could prevent and/or reduce the incidence of $A D$.

\section{Acknowledgements}

We thank the support from National Nature Science Foundation of China (\#31100745) and the CQCBE Project KJ110502.

\section{References}

[1] World Alzheimer Report 2014 Dementia and Risk Reductio, http://www.alz.co.uk/research/World Alzheimer Report 2014.pdf (September 2014).

[2] Alzheimer's Association, Alzheimer's \& Dementia 10 (2014) 47-92.

[3] M. Gatz, C.A. Reynolds, L. Fratiglioni, B. Johansson, J.A. Mortimer, S. Berg, A. Fiske, N.L. Pedersen, Archives of general psychiatry 63 (2006) 168-174.

[4] R.E. Tanzi, Cold Spring Harbor perspectives in medicine 2 (2012) 006-296.

[5] A. Goate, J. Hardy, Journal of neurochemistry 120 (2012) 3-8.

[6] M. Gatz, J.Y. Jang, I.K. Karlsson, N.L. Pedersen, Advances in Behavior Genetics 1 (2014) 201-231. 
[7] H. Amieva, H. Mokri, M. Le Goff, C. Meillon, H. Jacqmin-Gadda, A. Foubert-Samier, J.-M. Orgogozo, Y. Stern, J.-F. Dartigues, Brain 137 (2014) 1167-1175.

[8] R. Deane, A. Sagare, K. Hamm, M. Parisi, S. Lane, M.B. Finn, D.M. Holtzman, B.V. Zlokovic, The Journal of clinical investigation 118 (2008) 4002-4013.

[9] K.G. Mawuenyega, W. Sigurdson, V. Ovod, L. Munsell, T. Kasten, J.C. Morris, K.E. Yarasheski, R.J. Bateman, Science 330 (2010) 1774-1774.

[10] P.E. Cramer, J.R. Cirrito, D.W. Wesson, C.Y. Daniel Lee, J.C. Karlo, A.E. Zinn, B.T. Casali, J.L. Restivo, W.D. Goebel, M.J. James, K.R. Brunden, D.A. Wilson, G. E. Landreth, Science 335 (2012) 1503-1506.

[11] H. Zhang, Q. Ma, Y. Zhang, H. Xu, Journal of neurochemistry 120 (2012) 9-21.

[12] Y. Zhang, R. Thompson, H. Zhang,H. Xu, 4:3 Mol. Brain (2011).

[13] H. Zheng, E.H. Koo, Mol. Neurodegener. 6 (2011) 27.

[14] R.W.Y. Choy, Z. Cheng, R. Schekman, Proceedings of the National Academy of Sciences 109 (2012) E2077-E2082.

[15] G.M. Cole, S.A. Frautschy, Neuron 51 (2006) 671-672.

[16] M. Citron, T. Oltersdorf, C. Haass, L. McConlogue, A.Y. Hung, P. Seubert, C. Vigo-Pelfrey, I. Lieberburg, D.J. Selkoe, Nature 360 (1992) 672-674.

[17] T. Jonsson, J.K. Atwal, S. Steinberg, J. Snaedal, P.V. Jonsson, S. Bjornsson, H. Stefansson, P. Sulem, D. Gudbjartsson, J. Maloney, K. Hoyte, A. Gustafson, Y. Liu, Y. Lu, T. Bhangale, R.R. Graham, J. Huttenlocher, G. Bjornsdottir, O.A. Andreassen, E.G. Jönsson, A. Palotie, T.W. Behrens, O.T. Magnusson, A. Kong, U. Thorsteinsdottir, R.J. Watts, K. Stefansson, Nature 488 (2012) 96-99.

[18] G. Di Fede, M. Catania, M. Morbin, G. Rossi, S. Suardi, G. Mazzoleni, M. Merlin, A.R. Giovagnoli, S. Prioni, A. Erbetta, C. Falcone, M. Gobbi, L. Colombo, A. Bastone, M. Beeg, C. Manzoni, B. Francescucci, A. Spagnoli, L. Cantù, E. Del Favero, E. Levy, M. Salmona, F. Tagliavini, Science 323 (2009) 1473-1477.

[19] C. Haass, A.Y. Hung, D.J. Selkoe, D.B. Teplow, Journal of Biological Chemistry 269 (1994) 1774117748.

[20] C. Nilsberth, A. Westlind-Danielsson, C.B. Eckman, M.M. Condron, K. Axelman, C. Forsell, C. Stenh, J. Luthman, D.B. Teplow, S.G. Younkin, J. Näslund, L. Lannfelt, Nature neuroscience 4 (2001) 887-893.

[21] G. Rossi, G. Giaccone, R. Maletta, M. Morbin, R. Capobianco, M. Mangieri, A.R. Giovagnoli, A. Bizzi, C. Tomaino, M. Perri, M. Di Natale, F. Tagliavini, O. Bugiani, A.C. Bruni, Neurology 63 (2004) 910912.

[22] P. Pasalar, H. Najmabadi, A.R. Noorian, B. Moghimi, A. Jannati, A. Soltanzadeh, T. Krefft, R. Crook, J. Hardy, Neurology 58 (2002) 1574-1575.

[23] E. Sieczkowski, I. Milenkovic, V. Venkataramani, R. Giera, T. Ströbel, R. Höftberger, P.P. Liberski, E. Auff, O. Wirths, T.A. Bayer, G.G. Kovacs, Journal of Alzheimer's Disease 44 (2015) 103-114.

[24] C.R. Muratore, H.C. Rice, P. Srikanth, D.G. Callahan, T. Shin, L.N.P. Benjamin, D.M. Walsh, D.J. Selkoe, T.L. Young-Pearse, Human molecular genetics 23 (2014) 3523-3536.

[25] M.C. Chartier-Harlin, F. Crawford, H. Houlden, A. Warren, D. Hughes, L. Fidani, A. Goate, M. Rossor, P. Roques, J. Hardy, M. Mullan, Nature 353 (1991) 844-846.

[26] J.R. Murrell, A.M. Hake, K.A. Quaid, M.R. Farlow, B. Ghetti, Archives of neurology 57 (2000) 885-887.

[27] X.L. Peng, L. Hou, S.H. Xu, Y. Hua, S.-J. Zhou, Y. Zhang, Y.-P. Zheng, Y.-H. Fu, Q. Xu, L.-S. Zhang, J. Wang, X.-T. Guan, J.-S. He, Neurobiology of aging 35 (2014) 2657. e1-2657.e6.

[28] D. Kaden, A. Harmeier, C. Weise, L.M. Munter, V. Althoff, B.R. Rost, P.W. Hildebrand, D. Schmitz, M. Schaefer, R. Lurz, S. Skodda, R. Yamamoto, S. Arlt, U. Finckh, G. Multhaup, EMBO molecular medicine 4 (2012) 647-659.

[29] W.T. Chen, C.J. Hong, Y.T. Lin, W.-H. Chang, H.-T. Huang, J.-Y. Liao, Y.-J. Chang, Y.-F. Hsieh, C.-Y. Cheng, H.-C. Liu, Y.-R. Chen, I. H. Cheng, PloS one 7 (2012) e35807. 
[30] P.M. Truong, M.H. Viet, P.H. Nguyen, C.-K. Hu, M.S. Li, The Journal of Physical Chemistry B 118 (2014) 8972-8981.

[31] M.H. Viet, P.H. Nguyen, P. Derreumaux, M.S. Li, ACS chemical neuroscience 5 (2014) 646-657.

[32] K.L. Puig, A.M. Floden, R. Adhikari, M.Y. Golovko, C.K. Combs, PloS one 7 (2012) e30378.

[33] H. Shimada, S. Ataka, T. Tomiyama, H. Takechi, H. Mori, T. Miki, Dementia and geriatric cognitive disorders 32 (2011) 45-54.

[34] M. Schöll, A. Wall, S. Thordardottir, D. Ferreira, N. Bogdanović, B. Långström, O. Almkvist, C. Graff, A. Nordberg, Neurology 79 (2012) 229-236.

[35] A.M. Remes, L. Laru, H. Tuominen, S. Aalto, N. Kemppainen, H. Mononen, K. Någren, R. Parkkola, J.O. Rinne, Archives of neurology 65 (2008) 540-544.

[36] W.E Klunk, H. Engler, A. Nordberg, Y. Wang, G. Blomqvist, D.P. Holt, M. Bergström, I. Savitcheva, G.F. Huang, S. Estrada, B. Ausén, M.L. Debnath, J. Barletta, J.C. Price, J. Sandell, B.J. Lopresti, A. Wall, P. Koivisto, G. Antoni, C.A. Mathis, B. Långström, Annals of Neurology 55 (2004) 306-319.

[37] N.M. Kemppainen, S. Aalto, I.A. Wilson, K. Någren, S. Helin, A. Brück, V. Oikonen, M. Kailajärvi, M. Scheinin, M. Viitanen, R. Parkkola, J.O. Rinne, Neurology 67 (2006) 1575-1580.

[38] M.N. Braskie, L.D. Medina, Y. Rodriguez-Agudelo, D.H. Geschwind, M.A. Macias-Islas, J.L. Cummings, S.Y. Bookheimer, J.M. Ringman, Neurobiology of aging 33 (2012) 424.e11-424.e21.

[39] Q. Jiang, C.Y.D. Lee, S. Mandrekar, B. Wilkinson, P. Cramer, N. Zelcer, K. Mann, B. Lamb, T.M. Willson, J.L. Collins, J.C. Richardson, J.D. Smith, T.A. Comery, D. Riddell, D.M. Holtzman, P. Tontonoz, G.E. Landreth, Neuron 58 (2008) 681-693.

[40] C.C. Liu, T. Kanekiyo, H. Xu, G. Bu, Nature Reviews Neurology 9 (2013) 106-118.

[41] D.J. Berlau, M.M. Corrada, E. Head, C.H. Kawas, Neurology 72 (2009) 829-834.

[42] T. Polvikoski, R. Sulkava, M. Haltia, K. Kainulainen, A. Vuorio, A. Verkkoniemi, L. Niinistö, P. Halonen, K. Kontula, New England Journal of Medicine 333 (1995) 1242-1248.

[43] Turner, Jonathan D., Konrad Beyreuther, and Franz Theuring, Springer Science \& Business Media 17 (1996).

[44] S. Kern, K. Mehlig, J. Kern, H. Zetterberg, D. Thelle, I. Skoog, L. Lissner, K. Blennow, A. BörjessonHanson, American journal of epidemiology 181 (2015) 214-217.

[45] M. Liu, C. Bian, J. Zhang, F.Wen, Scientific reports 4 (2014) 4383.

[46] D.G. Cook, J.B. Leverenz, P.J. McMillan, J.J. Kulstad, S. Ericksen, R.A. Roth, G.D. Schellenberg, L.-W. Jin, K.S. Kovacina, S. Craft, The American journal of pathology 162 (2003) 313-319.

[47] Y.Y. Lim, V.L. Villemagne, S.M. Laws, R.H. Pietrzak, P.J. Snyder, D. Ames, K.A. Ellis, K. Harrington, A. Rembach, R.N. Martins, C.C. Rowe, C.L. Masters, P. Maruff, Molecular psychiatry (2014).

[48] V.K. Ramanan, S.L. Risacher, K. Nho, S. Kim, S. Swaminathan, L. Shen, T.M. Foroud, H. Hakonarson, M.J. Huentelman, P.S. Aisen, R.C. Petersen, R.C. Green, C.R. Jack, R.A. Koeppe, W.J. Jagust, M.W. Weiner, A.J. Saykin, Molecular psychiatry 19 (2014) 351-357.

[49] E.M. Reiman, R.J. Caselli, L.S. Yun, K. Chen, D. Bandy, S. Minoshima, S.N. Thibodeau, D. Osborne, New England Journal of Medicine 334 (1996) 752-758.

[50] E.M. Reiman, K. Chen, G,E, Alexander, R.J. Caselli, D. Bandy, D. Osborne, A.M. Saunders, J. Hardy, Proceedings of the National Academy of Sciences of the USA 102 (2005) 8299-8302.

[51] H.D. Protas, K. Chen, J.B.S. Langbaum, A.S. Fleisher, G.E. Alexander, W. Lee, D. Bandy, M.J. de Leon, L. Mosconi, S. Buckley, D. Truran-Sacrey, N. Schuff, M.W. Weiner, R.J. Caselli, E.M. Reiman, JAMA neurology 70 (2013) 320-325.

[52] E.M. Reiman, K. Chen, X. Liu, D. Bandy, M. Yu, W. Lee, N. Ayutyanont, J. Keppler, S.A. Reeder, J.B.S. Langbaum, G.E. Alexander, W.E. Klunk, C.A. Mathis, J.C. Price, H.J. Aizenstein, S.T. DeKosky, R.J. Caselli, Proceedings of the National Academy of Sciences of the USA 106 (2009) 6820-6825.

[53] E.M. Reiman, K. Chen, G.E. Alexander, R.J. Caselli, D. Bandy, D. Osborne, A.M. Saunders, J. Hardy, Proceedings of the National Academy of Sciences of the USA 101 (2004) 284-289. 
[54] C. Fennema-Notestine, M.S. Panizzon, W.R. Thompson, C.-H. Chen, L.T. Eyler, B. Fischl, C.E. Franz, M.D. Grant, A.J. Jak, T.L. Jernigan, M.J. Lyons, M.C. Neale, L.J. Seidman, M.T. Tsuang, H. Xian, A.M. Dale, W.S. Kremen, Journal of Alzheimer's Disease 26 (2011) 49-60.

[55] J.A. Brown, K.H. Terashima, A.C. Burggren, L.M. Ercoli, K.J. Miller, G.W. Small, S.Y. Bookheimer, Proceedings of the National Academy of Sciences of the USA 108 (2011) 20760-20765.

[56] M.W. Bondi, W.S. Houston, L.T. Eyler, G.G. Brown, Neurology 64 (2005) 501-508.

[57] M.M. Machulda, D.T. Jones, P. Vemuri, E. McDade, R. Avula, S. Przybelski, B.F. Boeve, D.S. Knopman, R.C. Petersen, C.R. Jack, Archives of neurology 68 (2011) 1131-1136.

[58] S.Y. Bookheimer, M.H. Strojwas, M.S. Cohen, A.M. Saunders, M.A. Pericak-Vance, J.C. Mazziotta, G.W. Small, New England journal of medicine 343 (2000) 450-456.

[59] J. Wang, X. Wang, Y. He, X. Yu, H. Wang, Y. He, Human brain mapping 36 (2015) 1828-1846.

[60] G. Struhl, I. Greenwald, Nature 398 (1999) 522-525.

[61] Y. Ye, N. Lukinova, M.E. Fortini, Nature 398 (1999) 525-529.

[62] S. Jayadev, J.B. Leverenz, E. Steinbart, J. Stahl, W. Klunk, C.-E. Yu, T.D. Bird, Brain 133 (2010) 11431154.

[63] S. Kumar-Singh, J. Theuns, B. Van Broeck, D. Pirici, K. Vennekens, E. Corsmit, M. Cruts, B. Dermaut, R. Wang, C. Van Broeckhoven, Human mutation 27 (2006) 686-695.

[64] M. Canevelli, P. Piscopo, G. Talarico, N. Vanacore, A. Blasimme, A. Crestini, G. Tosto, F. Troili, G.L. Lenzi, A. Confaloni, G. Bruno, Neuroscience \& Biobehavioral Reviews 42 (2014) 170-179.

[65] G. Binetti, S. Signorini, R. Squitti, A. Alberici, L. Benussi, E. Cassetta, G.B. Frisoni, L. Barbiero, E. Feudatari, F. Nicosia, C. Testa, O. Zanetti, M. Gennarelli, D. Perani, D. Anchisi, R. Ghidoni, P.M. Rossini, Annals of neurology 54 (2003) 832-836.

[66] G. Marcon, G. Giaccone, C. Cupidi, M. Balestrieri, C.A. Beltrami, N. Finato, P. Bergonzi, S. Sorbi, O. Bugiani, F. Tagliavini, Journal of Neuropathology \& Experimental Neurology 63 (2004) 199-209.

[67] U. Müller, P. Winter, C. Bolender, D. Nolte, Journal of Alzheimer's Disease 42 (2014) 109-113.

[68] Y. Qi, M. Morishima-Kawashima, T. Sato, et al., Biochemistry 42 (2003) 1042-1052.

[69] P. Koch, I.Y. Tamboli, J. Mertens, P. Wunderlich, J. Ladewig, K. Stüber, H. Esselmann, J. Wiltfang, O. Brüstle, J. Walter, The American journal of pathology 180 (2012) 2404-2416.

[70] K. V. Nguyen, Biomolecular concepts 6 (2015) 11-32.

[71] R. Fluhrer, A. Fukumori, L. Martin, et al., Journal of Biological Chemistry 283 (2008) 30121-30128.

[72] T. Saito, T. Suemoto, N. Brouwers, K. Sleegers, S. Funamoto, N. Mihira, Y. Matsuba, K. Yamada, P. Nilsson, J. Takano, M. Nishimura, N. Iwata, C. Van Broeckhoven, Y. Ihara, T.C. Saido, Nature neuroscience 14 (2011) 1023-1032.

[73] M. Shimojo, N. Sahara, T. Mizoroki, S. Funamoto, M. Morishima-Kawashima,T. Kudo, M. Takeda,Y. Ihara, H. Ichinose, A. Takashima, Journal of Biological Chemistry 283 (2008) 16488-16496.

[74] D. Xia, H. Watanabe, B. Wu, S.H. Lee, Y. Li, E. Tsvetkov, V.Y. Bolshakov, J. Shen, R.J. Kelleher, Neuron 85 (2015) 967-981.

[75] M. Cacquevel, L. Aeschbach, J. Houacine, P.C. Fraering, PloS one 7 (2012) e35133.

[76] M.A. Fernandez, J.A. Klutkowski, T. Freret, M.S. Wolfe, Journal of Biological Chemistry 289 (2014) 31043-31052.

[77] M. Okochi, S. Tagami, K. Yanagida, M. Takami, T.S. Kodama, K. Mori, T. Nakayama, Y. Ihara, M. Takeda, Cell reports 3 (2013) 42-51.

[78] Y. Ohki, N. Shimada, A. Tominaga, S. Osawa, T. Higo, S. Yokoshima, T. Fukuyama, T. Tomita, T. Iwatsubo, Molecular Neurodegeneration 9:7 (2014).

[79] E.M. Reiman, Y.T. Quiroz, A.S. Fleisher, K. Chen, C. Velez-Pardo, M. Jimenez-Del-Rio, A.M. Fagan, A.R. Shah, S. Alvarez, A. Arbelaez, M. Giraldo, N. Acosta-Baena, R.A. Sperling, B. Dickerson, C.E. Stern, V. Tirado, C. Munoz, R.A. Reiman, M.J. Huentelman, G.E. Alexander, J.B.S. Langbaum, K.S. Kosik, P.N. Tariot, F. Lopera, The Lancet Neurology 11 (2012) 1048. 
[80] W.E. Klunk, J.C. Price, C.A. Mathis, N.D. Tsopelas, B.J. Lopresti, S.K. Ziolko, W. Bi, J.A. Hoge, A.D. Cohen, M.D. Ikonomović, J.A. Saxton, B.E. Snitz, D.A. Pollen, M. Moonis, C.F. Lippa, J.M. Swearer, K.A. Johnson, D.M. Rentz, A.J. Fischman, H.J. Aizenstein, S.T. DeKosky, The Journal of neuroscience 27 (2007) 6174-6184.

[81] J. Koivunen, A. Verkkoniemi, S. Aalto, A. Paetau, J.-P. Ahonen, M. Viitanen, K. Någren, J. Rokka, M. Haaparanta, H. Kalimo, J. O. Rinne, Brain 131 (2008) 1845-1853.

[82] N.S. Ryan, S. Keihaninejad, T.J. Shakespeare, M. Lehmann, S.J. Crutch, I.B. Malone, J.S. Thornton, L. Mancini, H. Hyare, T. Yousry, G.R. Ridgway, H. Zhang, M. Modat, D.C. Alexander, M.N. Rossor, S. Ourselin, N.C. Fox, Brain 136 (2013) 1399-1414.

[83] L. Mosconi, S. Sorbi, M.J. de Leon, Y. Li, B. Nacmias, P.S. Myoung, W. Tsui, A. Ginestroni, V. Bessi, M. Fayyazz, P. Caffarra, A. Pupi, Journal of Nuclear Medicine 47 (2006) 1778-1786.

[84] R. Sala-Llonch, J. Fortea, D. Bartres-Faz, B. Bosch, A. Llado, C. Pena-Gomez, A. Antonell, F. Castellanos-Pinedo, N. Bargallo, J.L. Molinuevo, R. Sanchez-Valle, Journal of Alzheimer's Disease 36 (2013) 165-175.

[85] N. Ertekin-Taner, N. Graff-Radford, L.H. Younkin, C. Eckman, M. Baker, J. Adamson, J. Ronald, J. Blangero, M. Hutton, S.G. Younkin, Science 290 (2000) 2303-2304.

[86] W.K. Scott, J.M. Grubber, P.M. Conneally, G.W. Small, C.M. Hulette, C.K. Rosenberg, A.M. Saunders, A.D. Roses, J.L. Haines, M.A. Pericak-Vance, The American Journal of Human Genetics 66 (2000) 922-932. 